\title{
MedicAl MisadVEnTURE AND ACCIDENT COMPENSATION IN NEW ZEALAND: AN INCENTIVES-BASED ANALYSIS
}

\author{
Bronwyn Howell
}

This article discusses the role of incentives in reducing the occurrence of medical misadventure. The author argues that appropriate incentives may induce the practice of insuring appropriate levels of precaution by sharing the costs of insufficient levels of precaution between those with the power to exert clinical precaution (practitioners) and monitor and enforce its exertion (administrative agencies), and the victims who otherwise bear the costs of inadequate levels of precaution being taken. The respective ability of tort-based and no-fault systems to achieve this level of care is discussed, and then applied in the New Zealand ACC situation.

The author concludes that from the available evidence, incentives associated with a fault-based system are extremely difficult, if not impossible, to replicate in a no-fault system. This is even harder to achieve when public funding of both the ACC and health systems further reduces the incentives potentially available when individuals must meet the cost of their own treatment and liability insurance.

\section{INTRODUCTION}

Under the provisions of New Zealand's no-fault, government-indemnified accident compensation scheme (ACC), victims who are injured as a consequence of medical misadventure receive compensation for their injuries. In exchange for the certainty of compensation, ACC legislation waives the right of victims to sue malfeasant practitioners for either compensation or exemplary damages in all but the most extreme cases of gross negligence or deliberate intention to cause harm. While the scheme has been successful in ensuring that compensation has been awarded to many victims for whom the transaction costs of seeking redress via a tort-based system would

* Victoria Management School, Victoria University of Wellington; and Research Associate, New Zealand Institute for the Study of Competition and Regulation Inc. The author wishes to acknowledge the helpful comments of Glenn Boyle, Lewis Evans and Neil Quigley on a previous version of this article. 
have been prohibitive, ${ }^{1}$ it is less certain that the no-fault elements of the scheme provide sufficiently strong incentives to either medical practitioners, their patients, or third party administrative agents, to take appropriate levels of care. ${ }^{2}$

Given that ACC imposes limitations upon the ability of tort- or contract-based instruments to provide incentives to those who have the power to change the outcomes for victims of medical misadventure, greater reliance must be placed upon overt monitoring and enforcement by administrative agencies in order for the system to maintain an efficient level of medical misadventure. However, overt monitoring and enforcement systems are costly and are imperfect substitutes for some of the outcomes that may be achieved utilising the incentives in tort and contract instruments. Total reliance on overt administrative mechanisms leaves the system vulnerable to risks of even higher levels of misadventure occurring, especially if the administrative mechanisms are poorly resourced. Furthermore, poor information flows within the system potentially conspire against both the detection and correction of negligent actions, ${ }^{3}$ and make the collection of information to design more effective systems problematic. ${ }^{4}$

This article discusses the role of incentives in reducing the occurrence of medical misadventure. It argues that appropriate incentives may induce the practice of ensuring appropriate levels of precaution by sharing the costs of insufficient levels of precaution between those with the power to exert clinical precaution (practitioners) and monitor and enforce its exertion (administrative agencies), and the victims who otherwise bear the costs of inadequate levels of precaution being taken. The respective ability of tort-based and no-fault systems to achieve this level of care is discussed, and then applied in the New Zealand ACC situation. Illustrations taken from recent medical misadventure cases, in particular that of Dr Michael Bottrill in reading the cervical smears of women in the Gisborne region in the 1990s, are used to analyse the incentives facing both medical practitioners and those charged with monitoring and enforcing the performance of both medical practitioners and the ACC system.

1 Patricia M Danzon New Zealand Accident Compensation Scheme: Lessons on No-Fault Compensation for Medical and Other Injuries (Wharton School, University of Pennsylvania, Philadelphia, 1990).

2 Daniel P Kessler The Economic Effects of the Liability System (Hoover Institution Essay in Public Policy, Stanford University, 1999) <http://www-hoover.stanford.edu/publications $>$ (last accessed 11 November 2004); Bronwyn Howell, Judy Kavanagh and Lisa Marriott "No-Fault Public Liability Insurance: Evidence from New Zealand" 9 Agenda 135.

3 Bronwyn Howell Medical Misadventure in New Zealand: Who Bears the Risks? (New Zealand Institute for the Study of Competitition and Regulation Working Paper, Wellington, 2001); Canice J Prendergast Consumers and Agency Problems (National Bureau of Economic Research Working Paper No W 8445, Cambridge (Mass), 2001) <http://papers.nber.org/papers> (last accessed 11 November 2004).

4 Danzon, above n 1. 
From the available evidence it appears that the incentives associated with a fault-based system are extremely difficult, if not impossible, to replicate in a no-fault system. This may be even harder to achieve when public funding of both the ACC and health systems further reduces the incentives potentially available when individuals must meet the costs of their own treatment and liability insurance. These issues should be considered in any changes to the medical misadventure claims process within ACC.

\section{EFFICIENT LEVELS OF NEGLIGENCE AND MISADVENTURE}

Negligence and misadventure will inevitably arise in relation to undertaking certain activities. At best, any legal regime can strive to design mechanisms that efficiently trade off the costs of prevention against the costs incurred as a result of the negligence or misadventure in such a way that the total costs to society are lowest. ${ }^{5}$

Higher investment in prevention mechanisms will reduce the number of occurrences. However, there comes a point where the marginal cost of preventing an additional incidence of negligence or misadventure equals the marginal benefit (the incremental value of the loss incurred as a result of one more instance of negligence) of it not occurring. This point is the "efficient" level of occurrence of negligence and misadventure. If fewer instances occur, then the level of investment in prevention is inefficiently high. In these circumstances, it is likely that otherwise beneficial actions are being avoided because over-caution is preventing normal operational risks from being undertaken, or resources that could be devoted more efficiently to other activities are being spent on monitoring the activities potentially subject to negligence or malfeasance. If more incidences occur, then the costs of negligence or misadventure borne by victims are higher than is efficient.

\section{THE CONTRACT AND TORTS APPROACHES}

Traditional approaches to setting the optimal level of negligence and misadventure for activities have relied upon tort law, and upon risk-sharing contracts between individuals, to allocate the costs amongst the individuals involved. When outcomes between parties can be foreseen, the party likely to be harmed as a result of an action by the other can design a contract that causes the other party to incur some of the costs of the harm, thereby reducing the likelihood of its occurrence. However, when the outcomes result from actions by groups or individuals who could not have foreseen ex ante the need to form a contract with each other (for example, an emergency procedure performed by a specific surgeon on an individual patient following an accident leads to a medical misadventure; a vehicle collision between two unacquainted parties results in losses due to the negligence of one party), tort law can be invoked to seek redress.

5 Steven Shavell Economic Analysis of Accident Law (Harvard University Press, Cambridge (Mass), 1987) 217. 
The two goals of tort law are to compensate the parties suffering loss and to provide potential loss-causers with incentives to avoid acts that incur loss. ${ }^{6}$ Tort law uses the instrument of compensation as a means of shifting the costs of negligent actions and misadventure from the victim onto the person who can best manage the risks of the negligent action or misadventure occurring. As the party controlling the level of risk now bears the costs of their loss-causing behaviour, those capable of managing risks will undertake higher levels of prevention; not through any altruistic motivation to reduce the losses incurred by the other parties, but because, as a result of being required to pay compensation, it now costs them personally when adequate precaution is not taken.

If the levels of compensation are set appropriately, then the potential loss-causers will increase precaution to the point where the level of negligence and misadventure is efficient. To invest any more in prevention will raise the costs of the potential loss-causer, but may cause the other party to incur costs if the action is not undertaken (for example, excessive caution by a medical practitioner leading to patients being denied treatment that would reduce their suffering). Neither party is satisfied with such an outcome - it is now in the interests of both parties to ensure that the action occurs. Likewise, a potential victim will exert inefficiently high levels of caution if the compensation level is set too low (for example refraining from seeking otherwise beneficial treatment, resulting in a "missing market" with the medical practitioner idle and the patient incurring further suffering) or invest in less than efficient levels of caution if the compensation is too high (for example putting pressure upon a practitioner to undertake high-risk or experimental treatments). Thus, if compensation levels are set appropriately, the incentives within the system ensure that an equilibrium level of negligence and misadventure is achieved.

\section{INSURANCE AND MORAL HAZARD}

Tort systems do not result in all cases of loss being pursued through the courts. If the costs of seeking compensation exceed the expected compensation, then harmed individuals will absorb the costs, meaning some negligent practitioners will not bear the costs of their actions (or inactions). Under such system, practitioners know that they do not have to be so careful with respect to minor losses, so their level of care decreases with a consequent increase in overall losses incurred. Moreover, if the potentially negligent practitioner can secure insurance cover to pay the costs resulting from being found liable in a tort action, then the costs of negligent actions are shifted from the individual practitioner alone onto all contributors to the insurance scheme. The individual faces even fewer incentives to be careful, raising the likelihood that a negligent action will occur and resulting in even more claims. If all practitioners respond in the same manner, then the total

6 Kessler, above n 2, 1. 
instances of loss will increase, and the costs of the insurance scheme are greater. This is the classic moral hazard consequence of insurance coverage. ${ }^{7}$

Where only potentially negligent practitioners contribute to the costs of insurance schemes, the increased costs are ultimately imposed upon all practitioners in the form of higher premiums. The practitioners as a group "internalise" the costs of their moral hazard behaviours, and will seek to increase their levels of precaution to reduce the premiums. However, there will always be less careful practitioners who will exert less care than the average. If these practitioners can be identified, and their premiums adjusted accordingly, then they face additional incentives to be careful and to reduce the loss-causing behaviours of colleagues, as they now internalise their greater costs. For such risk-sharing to be efficient, less careful practitioners must be able to be identified and the cost consequences of their less-than-careful practices determined, either from past performance (experience-rating), or by other overt mechanisms such as directly observing their practice and punishing poor performance (overt monitoring and enforcement) and imposing compulsory retraining requirements (education).

\section{MONITORING AND ENFORCEMENT}

Monitoring and enforcement, however, is imperfect. Unless all negligent actions can be detected and all breaches acted upon, then there will always be practitioners who do not bear the costs of their lack of precaution. Unobserved practitioners may lower their level of care. In order to induce all practitioners to act with due care, even though they are not observed at all times, the tort system relies upon exemplary damages awards against those practitioners who are detected to act as an incentive to those who are not. All practitioners increase their levels of care, as the costs of being caught are much greater than simple compensation for detected patient losses. The costs of lack of caution by both detected and undetected practitioners are borne by the practitioners who are detected and punished. The threat of being detected in the future, and being made to bear a disproportionately high share of the costs, thus acts as an ex ante incentive to take greater care. Insurance schemes can utilise screening mechanisms and instruments such as co-payments in order to identify more risky practitioners and to endeavour to make them bear more of the costs of their less cautious behaviours, but these are not perfect either. Insurance schemes too benefit from the punitive mechanisms of the tort process to induce efficient levels of precaution where the mechanisms of the scheme itself are insufficient to either incentivise efficient levels of precaution or detect instances of potential or actual negligence.

In the absence of a tort system, alternative monitoring, enforcement and punishment systems (for example professional disciplinary committees; the Accident Compensation Corporation; Office of the Health and Disability Commissioner; Occupational Safety and Health) can provide

7 Paul Milgrom and John Roberts Economics, Organization and Management (Prentice Hall, New Jersey, 1992) $167-70$ 
substitutes. However, such actions may cost as much as, or even more than, the equivalent tort processes. Further, when actions are spread across a wide range of different agencies, the total costs may not be fully transparent, as no one agency absorbs the total costs of the monitoring and enforcement activities. ${ }^{8}$ Without the added impetus of securing compensation, the advantages of one monitoring and enforcement agency pursuing such cases may be fewer. Hence the threshold of negligence at which such cases are brought tends to be high, with the penalties imposed upon practitioners found guilty being quite severe to achieve the desired deterrence effect.

\section{INFORMATION AND THE EFFECTS OF THIRD PARTIES}

Effective monitoring and enforcement requires information to be in the right place at the right time. Danzon notes that the bodies most often charged with undertaking overt monitoring and enforcement tend to be the least likely to have access to the information required to deliver an effective monitoring process in respect of individual processes, and are also unlikely to be collecting information in their monitoring and enforcement tasks that is conducive to developing more effective, safer methods and techniques. ${ }^{9}$

Generally, only the parties to the action have information about the amount of care taken. If an information asymmetry exists between the party who should take care and the potential victim, then the victim is in a poor position to assess the standard of care taken. This is especially true in the case of medical treatment, where a well-established asymmetry exists between patients and doctors. ${ }^{10}$ Such parties generally must rely upon more informed third-party agents (for example statutorily-appointed administrators, insurance company employees or professional associations) to monitor and enforce performance standards on their behalf. However, unless they are present at the action, third party agents become reliant upon information shared by the uninformed party to detect actual breaches of care. ${ }^{11}$ Information exchange is seldom perfect. The complete set of relevant facts is rarely exchanged. Also, fraudulent claims must be detected and eliminated.

Further, if the costs of sharing information exceed the losses, then even if perfect information exchange is possible, not all losses will be notified and acted upon. Prendergast demonstrates that in order for an uninformed principal to obtain information on the performance of an agent from a third party, the principal must actually pay the third party an amount that exceeds the transaction

8 Adrian Towse and Patricia Danzon, "Medical Negligence and the NHS: An Economic Analysis" (1999) 8 Health Economics 98.

9 Patricia Danzon "Liability for Medical Malpractice" in J Newhouse and A Culyer (eds) Handbook of Health Economics (vol 1, Elsevier, Amsterdam, 2000) 1394.

10 R Vaithianathan "The Failure of Corporatisation: Public Hospitals in New Zealand" (1999) 6 Agenda 83.

11 While routine performance appraisals and quality audits are useful for detecting habitual poor practice, these mechanisms are not necessarily good at detecting or acting upon isolated or episodic instances of lack of care. 
costs of exchange incurred by the third party in order for the informed third party to reveal the information. ${ }^{12}$ A notable New Zealand example is the "200 per cent guarantee" provided by New World supermarkets. By refunding the customer for a faulty product and providing an additional reward of the value of the faulty product, the supermarket owner incentivises customers to provide information about product quality (or alternatively, the supermarket owner purchases information) as a means of monitoring the performance of employees whose actions can affect the quality of the products sold. Such payments increase the costs of overt monitoring activities. Unless they are made, the likelihood of all miscreant practitioners being identified and their levels of care enforced is slight, leading to average levels of care declining, and losses rising. Even more (costly) monitoring and information purchase is required to reduce the level of loss, raising the costs of prevention and decreasing efficiency.

In a system reliant upon the actions of third parties to detect, monitor and enforce standards, the whole range of incentives facing these third parties in their capacity as agents of both the patient and other principals must also be considered. If third parties have conflicting roles (for example, a professional organisation with a fiduciary duty to the patient and a collegial responsibility to the practitioner and the profession is agent to both parties in the treatment; an administrative agent may have a duty to act in the patient's interests, even though the action may be embarrassing and/or costly for the agency that employs the agent, such as an insurance company or a public service entity and its politician principals), then prioritising amongst these agencies may result in the patient agency being subjugated to other responsibilities if the incentives from those other responsibilities are stronger. ${ }^{13}$ This is especially likely to occur within administrative agencies where there is no ability to share the costs of patient risks directly with agents (due, for example, to crown immunity in the case of public service delivery or absence of performance-based remuneration). ${ }^{14}$ Such conflicts often manifest themselves in public agencies in the form of information being withheld ${ }^{15}$ and slow response in the case of actions that are raised. ${ }^{16}$ While these incentives do not directly impinge upon the likelihood of any individual case of negligence occurring, they raise the total costs of negligence by allowing habitually negligent practitioners to continue practising longer than might otherwise be the case if patient incentives had been given priority.

12 Prendergast, above n 3, 2.

13 B Holstom and P Milgrom "Multitask Principal - Agent Analyses: Incentive Contracts, Asset Ownership and Job Design" (1991) 7 J L and Econ Organisation 24.

14 Howell, above n 3.

15 Prendergast, above $\mathrm{n} 3$.

16 Murray J Horn The Political Economy of Public Administration: Institutional Choice in the Public Sector (Cambridge University Press, Cambridge, 1995). 


\section{EDUCATION}

Education programmes and other forms of information provision to potentially negligent practitioners can reduce the instances of negligence occurring. In practice, and in public service delivery in particular, they are often employed as substitutes for other activities such as overt monitoring and enforcement, within the constraints of the available budget. ${ }^{17}$ However, education is an imperfect substitute for overt monitoring and enforcement because without information derived from observation, purchase from or voluntary provision of information by victims about the types of behaviours that are leading to losses from negligence, the design of the education programme may have no noticeable effect upon the behaviours that are causing the negligence to occur. It is also an imperfect substitute for incentives.

In order to reduce the costs and incidence of negligence to the same extent as incentives or overt monitoring and enforcement, at equal or greater efficiency, the education programme must address exactly the same behaviours that incentives, monitoring and enforcement address, at the same or lesser cost, or address loss-causing behaviours that neither incentives nor monitoring and enforcement can address. Given the inevitable information asymmetry that occurs between the designers of education systems and victims, it seems extremely unlikely that this objective could ever be achieved.

Education programmes are at best a complement to incentives and monitoring and enforcement activities in reducing the instances of undesirable behaviour. At worst, if they focus on irrelevant activities they may be a costly waste of resources having no effect upon the occurrence of negligence or the exercise of due care. Unless there are good information flows from actual monitoring (for example extensive and costly management information systems reporting on all possible actions and outcomes) and from victims, the education system designers may not be aware of the behaviours that are causing most of the loss, and may instead focus the education effort on other activities that may be totally unrelated to negligent behaviours resulting in harm to individuals (for example procedural rather than clinical factors). Further, without substantial investment in management information systems, even if the likely negligent behaviours can be and are accurately identified, administratively-determined prioritisation of the activities targeted by education programmes may not reflect the actual risks or costs of occurrence. Education systems thus risk spending resources targeting problems as perceived by administrators, which are not necessarily the most costly or the most important contributors to the incidence of negligence. ${ }^{18}$

Secondly, efficient education as a means of reducing negligence requires identification of the practitioners most in need of the education, and mechanisms that make it costly or difficult for these

17 David C Mare and Kerry L Papps "The Effects of Occupational Safety and Health Interventions" (2002) Labour Market Bulletin 101, 113.

18 Danzon, above $\mathrm{n} 1$. 
practitioners to avoid participating in the education programme. Unless there are good monitoring mechanisms detecting these practitioners, the only way of being certain that less careful practitioners receive the education is to make it compulsory for all practitioners to participate. ${ }^{19}$ This crude method results in too much of the education resource being spent on practitioners who are at low risk of acting negligently, reducing the resources that could be spent more effectively on those most in need of the education services. In order to reduce negligence to the "efficient" level through education alone, too much will be spent on education of practitioners who would not act negligently in any case. By comparison, incentives specifically target the behaviours of negligent practitioners, without distorting the behaviours of those who are already adopting appropriate levels of care.

\section{A BALANCED APPROACH}

In practice, given all of these complexities, a combination of overt monitoring and enforcement, contracts that share the risks between parties, insurance mechanisms, tort action and education is required to induce an efficient level of negligence and misadventure. If for any reason any one of the mechanisms is precluded (for example, as in a no-fault system), in order to maintain the same levels of loss, there must be compensating rises in the amount of activity in the remaining mechanisms. If this does not occur, the inevitable consequence will be a rise in the costs of negligence and misadventure above the efficient level.

The defining feature of fault-attributing schemes is that the threat of liability for nonperformance applies to all parties. By removing the nexus between cause and compensation, nofault schemes sever the link between the potential for individuals (be they practitioners, administrators or individuals with whom practitioners and administrators interact) to cause loss and the costs of their actions. It is very costly to try and replicate this nexus solely with administrative systems, and it is likely to be impossible to do so. In order to replicate the same outcomes as a comparable contract- and tort-based system, efficient no-fault mechanisms must include additional administrative (monitoring and enforcement, and education) systems not present in typical contract and tort systems, in order to preserve the incentives for appropriate loss-avoidance. ${ }^{20}$ No-fault schemes therefore tend to be less effective in circumstances where there are significant opportunities for individuals to alter the costs of the scheme by acting opportunistically or where monitoring and enforcement is either extremely costly or highly unlikely to be an effective curb on moral hazard

19 In Pegasus Health, a Christchurch collective of general practitioners, all practitioners are required to participate in a certain number of education programmes in a given year: Baden Ewart and David Moore "Global Budget Management: Effectiveness and Lessons for DHBs" (Health Services Research Centre Seminar, School of Government, Victoria University of Wellington, 27 June 2004). Compliance is assured in part because the practitioners are paid to attend.

20 Kessler, above n 2, 13. 
behaviours. ${ }^{21}$ In these circumstances, efficient levels of precaution may be achievable only within a regime that includes the use of individual incentives. ${ }^{22}$

\section{THE NEW ZEALAND ACC MEDICAL MISADVENTURE CONTEXT}

In New Zealand, the tort framework for setting the level of negligence and misadventure in respect of personal injury, with a few exceptions, has been replaced by a universal, no-fault, government-underwritten accident compensation insurance scheme (ACC). ACC provides certainty of compensation for anyone injured as a result of an accident, irrespective of who caused the harm. However, recourse to the tort system to seek compensation from the individual whose actions caused harm is removed for personal injury victims. The compulsory nature of the ACC scheme and the statutory monopoly aspects of its provisions also preclude any person from entering into any voluntary contractual arrangement with any other in order to share the costs and risks associated with personal injury. The administrative provision of all services related to personal injury by stateowned or state-mandated agencies precludes any direct accountability between patients and individual state agents charged with both monitoring and enforcing standards of care and acting upon proven breaches. ${ }^{23}$ Hence, the only mechanisms available to influence the levels of precaution undertaken are overt monitoring and enforcement and education.

The no-fault nature of ACC insulates the parties who cause harm against the personal consequences of taking inappropriate levels of precaution, as they no longer have to personally bear the costs of compensating their victims. Unlike typical practitioner liability insurance schemes, the compensation costs of ACC medical misadventure are spread via levies and taxes amongst not only all potential causers of harm but also their potential victims. Consequently, practitioners are subject to weak checks on moral hazard due to the wide sharing of risks and costs with others, while potential victims also face few incentives to take due care in circumstances where their actions are able to influence the outcome.

Relative to liability-based schemes, there are fewer incentives for any individuals under the New Zealand ACC system to take care. Without significant compensatory increases in overt monitoring, enforcement and education activities, the level of negligence and misadventure and consequent costs will be higher. ${ }^{24}$ Inefficiently low levels of precaution are likely to be taken, resulting in more instances of loss, but with greater certainty that the injured individuals will be compensated for the losses they incur. The alteration to incentives applies to all parties, and in all circumstances where

21 Steven Shavell "An Analysis of Causation and the Scope of Liability in the Law of Torts" (1980) 9 J Leval Stud 463 ["An Analysis of Causation and the Scope of Liability in the Law of Torts"]. Steven Shavell "Strict Liability Versus Negligence" (1980) J Legal Stud 1.

22 Howell, Kavanagh and Marriott, above n 2, 147.

23 Howell, above $\mathrm{n} 3$.

24 Kessler, above n 2, 14. 
personal injury may arise, including workplace injuries, vehicle and sporting injuries, nonworkplace injuries and medical misadventure.

\section{APPLICATION TO MEDICAL MISADVENTURE}

The New Zealand ACC scheme provides specific cover for injuries that arise as a consequence of a medical practitioner (for example a doctor, nurse, physiotherapist, or pharmacist) providing medical care and treatment to an individual. The no-fault New Zealand approach to medical misadventure differs significantly from most other common-law countries (for example, Australia, the United Kingdom and the United States), where a combination of contracts between patients and practitioners and tort law assigns compensation in the event of negligence leading to personal injury, and provides incentives to all parties (both practitioners and patients) to exercise precaution.

\section{TORT AND EXCESSIVE PRECAUTION}

No-fault insurance schemes are particularly useful in providing certainty of compensation to the injured party where circumstances mean that it is difficult for parties to contract with each other ex ante for the risks of negligence. Thus, they are well-suited to circumstances involving nonconsenting strangers, such as in motor vehicle accidents. However, the circumstances under which a consenting patient seeks medical treatment from a specific practitioner would appear to be wellsuited to seeking an ex ante contractual allocation of risks, with fault-attributing tort actions being used to assign the costs of negligence. ${ }^{25}$ While it may be difficult to establish exact causation of the injury in the case of medical treatment due to the highly variable outcomes from the same treatment on different individuals, application of standards of due care have typically been used in determining negligence by medical practitioners in tort actions in foreign jurisdictions. ${ }^{26}$

At least with regard to medical misadventure, ACC stands as a significant anomaly in personal injury insurance markets. It could be expected that, absent any greater levels of administrative activities, the no-fault New Zealand system would deliver substantially higher levels of medical misadventure-related injury due to the lowered incentives to take care relative to other jurisdictions. However, it is argued that fault-based schemes may lead to another unsatisfactory outcome in terms of over-high levels of precaution being taken. ${ }^{27}$ In some jurisdictions, following court decisions requiring very large levels of compensation to be paid by doctors to patients for adverse medical events, practitioner liability insurance premiums have increased. In extreme cases, medical practitioners have declined to treat patients in order to preclude themselves being found personally liable for compensation in the event of an adverse, but not especially rare, event over which the

25 An Analysis of Causation and the Scope of Liability in the Law of Torts, above $\mathrm{n} 21$.

26 Credit Suisse First Boston Accident Compensation: Options for Reform (New Zealand Business Round Table, Wellington, 1998) 113-121.

27 Kessler, above n 2, 2. 
practitioner has no control. Such over-investment in precautionary practices and the poor empirical record of tort-based schemes in delivering both compensation and deterrence ${ }^{28}$ has led some to suggest that a no-fault scheme can deliver a better outcome in the case of medical misadventure. ${ }^{29}$ Others, however, contend that the increase in precautionary practice has arisen due to judicial activism raising the acceptable standard of due care and awarding increasing levels of compensation to overcome perceived inequities in the level of compensation offered by insurance schemes. ${ }^{30}$

\section{MONITORING AND ENFORCEMENT}

While a no-fault system may restrict over-investment in precaution, unless New Zealand has substantially stronger overt monitoring and enforcement mechanisms than comparable foreign jurisdictions, the New Zealand system is likely to be exhibiting an inefficiently high number of instances of medical misadventure due to lower standards of care being taken. Documentary evidence is limited and comparisons with foreign jurisdictions are difficult due to differences in the way statistics are collected. However, evidence that is available tends to support the contention that the occurrence of medical misadventure in New Zealand is high, and increasing in both number and cost. Davis and others find that "4.5 per cent of all admissions in New Zealand public hospitals were associated with highly preventable adverse events", 31 compared to detected negligence rates of 3.7 per cent in New York hospital admissions. ${ }^{32}$ ACC statistics report an increase in medical misadventure costs of $\$ 15$ million between 1995 and 2001. The total costs for medical misadventure in the year ended June 2001 were \$22.09 million and the number of medical misadventure claims in the 2000-2001 year was 12 per cent higher than in the 1998-1999 year. ${ }^{33}$

Furthermore, there is little anecdotal support for the contention that the extent of monitoring and enforcement in New Zealand with respect to medical misadventure is substantially greater than that observed in countries with fault-based systems. Rather, the suggestion is that New Zealand may be subject to both lower standards of care and lower standards of monitoring. Specifically, the Ministerial Inquiry into the Under-Reporting of Cervical Smear Abnormalities in the Gisborne

28 Peter Huber Liability: The Legal Revolution and its Consequences (Basic Books, New York, 1988).

29 John Wren "More Money or More Effectiveness and Efficiency" 5 ELB 83.

30 Credit Suisse First Boston, above n 26.

31 P Davis and Others Adverse Events in New Zealand Public Hospitals: Principal Findings from a National Survey (Ministry of Health, Wellington, 2001) iii ["Adverse Events in New Zealand Public Hospitals: Principal Findings from a National Survey"] available at <http://www.moh.govt.nz $>$ (last accessed 5 December 2004)

32 Danzon, above, n 9, 1351.

33 Accident Compensation Corporation Annual Report (Accident Compensation Corporation, Wellington, 2001). 
Region $^{34}$ found significant evidence of both low standards of care and poor design of monitoring and enforcement mechanisms. ${ }^{35}$

First, while New Zealand pathologist colleagues of Dr Michael Bottrill testified in the High Court that his error rates were within acceptable bounds, international expert evidence presented to the inquiry found that they were substantially lower than internationally acceptable standards. This casts doubt upon the acceptability of practice standards exercised by all New Zealand pathologists, who set the admission standards for practising in New Zealand and monitor and enforce the performance of each other as peers. The Inquiry's findings led to the recommendation that a full audit of the programme be undertaken to determine whether the readings of any other pathologists also fell within unacceptable levels. ${ }^{36}$ The findings also raise the issue of a conflict of interest, involving the members of Royal Australasian College of Pathologists in their fiduciary duty to patients and society to monitor and enforce any practitioner's performance standards whilst simultaneously acting in the interests of the College itself. It is conceivable that in order to protect the reputation of the College and the ongoing ability for members to both self-regulate and derive revenue from government contracts associated with the operation of the National Cervical Screening

34 A P Duffy, D K Barrett and M A Duggan Report of the Ministerial Inquiry into the Under-Reporting of Cervical Smear Abnormalities in the Gisborne Region (Prepared for the Minister of Health, 2001) $<$ http://www.csi.org.nz> (last accessed 11 November 2004).

35 For a period between 1990 and 1996, Dr Michael Bottrill was contracted to provide pathology services to the New Zealand Cervical Screening Programme in the city of Gisborne. It was found that over this period, Dr Bottrill had been practising at a standard substantially below that which could be expected of a pathologist. Consequently, many women whose smear tests he read were falsely cleared of having cervical abnormalities. Some of these women went on to develop invasive cancer, which was eventually found to be a medical misadventure for which they were eligible for compensation. The Ministerial Inquiry found that, while Dr Bottrill had acted negligently, the design and operation of the New Zealand National Cervical Screening Programme was substandard. Despite the misgivings of some officials and medical professionals, the scheme was allowed to "go live" in 1990 in order to meet political obligations. Poor design issues related to the inability of the system to match the Cancer Register with the Cervical Screening Register to identify women who had been screened and who went on to develop invasive cancer. Thus, it was impossible to measure the success of the screening programme in reducing the instances of invasive cancer relative to women who had not been screened. Furthermore, information on the relative performance of pathologists in accurately reading smears was ignored. Matching the databases and identifying trends in the rate at which specific pathologists' patients went on to develop invasive cancer would have singled out negligent practitioners. The inquiry also found that a further implicating factor delaying action was the repeated restructuring of the health system over the 1990s. High staff turnover and confusion about the responsibilities of various agencies led to further delays in acting upon information.

36 At the time of writing, nearly three years after the Ministerial Inquiry, a full audit has yet to be undertaken. 
Programme, the members testifying prioritised the incentives of membership over the interests of patients and the public. ${ }^{37}$

Secondly, the Inquiry found significant flaws in the design and operation of the Cervical Screening Programme that prevented the levels of monitoring and enforcement required for a bestpractice screening programme to be delivered in New Zealand. The levels of monitoring and enforcement were not greater than international counterfactuals, as would be expected in a welldesigned no-fault system, but were in fact of a demonstrably lower standard. It is noted that the recommendations from the Inquiry were to raise the New Zealand monitoring and enforcement standards to meet, not exceed, the international benchmarks.

\section{INFORMATION, INCENTIVES AND INSTITUTIONAL DESIGN}

The no-fault nature of ACC places almost total reliance upon effective information flows for the design and operation of monitoring and enforcement mechanisms. Yet the design of the system is complex, and offers few incentives for effective information flows in order to support these processes. While victims and their families may be highly motivated to share information about actual medical misadventure outcomes in order to receive compensation, this information becomes available only after an injury has occurred. The compulsory nature of the scheme combined with the existence of a single monopoly provider significantly reduces any incentives for those who have cover under the scheme to undertake any monitoring of the scheme unless actual injury occurs, compared to a scheme where fault can be attributed.

In respect of medical misadventure, State involvement in funding the vast majority of treatment (in New Zealand the Government meets 78 per cent of medical expenditure ${ }^{38}$ ) further reduces the incentives for recipients of treatment to undertake any search and/or monitoring of their providers, as in many cases there is no choice of provider or indeed of medical misadventure coverer. The optimal individual response to a subsidy is for patients to free-ride on the monitoring efforts of other patients and the monitoring efforts of their public sector administrative agents who are delegated to search, select, remunerate and monitor the treatment provider. ${ }^{39}$ Yet it is seldom in the interests of these agents to collect and disseminate information that may be detrimental to their continuing to receive income. ${ }^{40}$ Relying upon individual, highly-motivated patients ("whistleblowers") to exert

37 Miriyana Alexander "Bottrill Cover-Up Astounds Lawyers: Doctors Closed Ranks" (26 September 1999) Sunday Star Times, Auckland, writes of members of the College "closing ranks" around Dr Bottrill by testifying in the High Court that his level of reading errors fell within an acceptable margin for competent cytopathologists, when an Australian review indicated that this was not the case.

38 John Hazeldine Health Expenditure Trends in New Zealand 1990-2002 (Ministry of Health, Wellington, 2004).

39 Milgrom and Roberts, above n 7, 294-298.

40 Prendergast, above n 3. 
sufficient effort to call negligent and malfeasant practitioners to account is unreliable. Consequently, in the New Zealand situation, relative to cases where the individual seeking medical treatment pays the full cost of the service, even greater importance must be placed upon the effectiveness of administrative processes to provide monitoring, enforcement and education, if the optimal level of medical misadventure is to be achieved.

Yet, perversely, once information has been made available via either patient revelation or agent observation, in the absence of either direct sharing of the risks and costs with the individuals responsible for administrative actions or explicit payment for the transfer of information, the incentives for the very large number of third party agents to use this information either to pursue negligent or malfeasant practitioners (enforcement) or to design improved monitoring and education systems are few. This is likely to lead to even less emphasis upon prevention, with much higher reliance being placed upon capturing information about actual occurrences of harm. In such an environment, monitoring and enforcement activities tend to occur not as a routine part of the administrative process but as a consequence of claims for compensation being made. The rise in levels of medical misadventure is reinforced and the collection and utilisation of information that would enable improvements in the design of institutional forms and processes is disincentivised.

Information-gathering and sharing amongst third party agents, if it is to occur at all, is thus likely to be costly. It will take much longer for poor practice to be identified and acted upon (if it is to occur at all), further increasing the total costs of misadventure. As negligent and malfeasant practitioners continue treating patients more patients are exposed to poor standards of care. Danzon finds that the costs of injury combined with the costs of collection and co-ordination of the necessary information may far exceed the costs of a fault-based system, and are less likely to be identified as they are spread over a wide number of disparate agencies. ${ }^{41}$ Even when misadventure is identified, it is not at all clear that the most effective remedy will be granted, simply because all the relevant information for the design of a remedy is not available.

Where a remedy is available, administrators face an incentive to increase their own monitoring effort and act upon the information collected. However, where no remedy is available, these individuals face fewer incentives to monitor. Monitoring and enforcement agencies, who cannot themselves directly recover the costs of loss from malfeasant practitioners but can spread the costs even further by increasing levies to all taxpayers, also face few incentives to reduce actual losses. In the face of a conflict of responsibilities, these agents face much stronger incentives to reduce the

41 For example, all of the Accident Compensation Corporation, Ministries of Health, Transport, Labour, Police, the Land Transport Safety Authority, 21 District Health Boards, the Office of the Health and Disability Commissioner, the Medical Association and other professional registration boards all have specific responsibilities to gather information, monitor and enforce practice, design systems and deliver education programmes related to accident compensation in New Zealand, and this is by no means a comprehensive list. Danzon, above n 9, 1351. 
costs of the scheme by adjusting levels of compensation paid, and reducing costs in the areas that they can manage - the levels of monitoring, enforcement and education. ${ }^{42}$

The Bottrill case demonstrates the lengthy delays that can arise within a publicly-funded health system even after questions have been raised about the competence of practitioners as a consequence of motivated patient (whistleblower) actions. Duffy and others indicate that questions were raised about Dr Bottrill's competence as early as 1991, with significant concerns being voiced in 1994 and again in 1996. ${ }^{43}$ Concerns were raised about elements of the design of the Cervical Screening Programme in 1989 before it was implemented. However, none of the State or medical fiduciary agencies acted upon the information to discipline Dr Bottrill or to investigate the standards of monitoring and enforcement associated with the Cervical Screening Programme, as none were sufficiently incentivised to pursue the matter. It was left to a patient who developed invasive cancer after having several smear tests incorrectly read as "clear" by Dr Bottrill to pursue the matter, through a court case in 1999 that was hampered by the provisions of ACC legislation precluding an award of exemplary damages. ${ }^{44}$ This produced sufficient publicity that a Ministerial Inquiry was instituted. $^{45}$ Further, the Bottrill case does not appear to be an isolated instance of administrative delays within both the public sector health agencies and medical registration bodies. Similar concerns have surrounded the case of Whangarei gynaecologist Dr Colin Parry ${ }^{46}$ and others, ${ }^{47}$ leading to the 2001 Inquiry into Medical Misadventure. ${ }^{48}$

\section{INCENTIVES, THE RIGHT TO SUE AND CONTRIBUTORY FAULT}

Access to the right to sue, irrespective of who pays for actual treatment, provides unique incentives for information about performance and standards of care to be collected and disseminated to those who can either act on the information or can personally benefit from it (for example, patients, insurance companies and administrative agencies seeking to reduce their costs by reducing instances of harm) in ways not achievable when there is no such right to sue. The type of information collected under a fault-based system differs from that collected under no-fault systems, ${ }^{49}$ as it tends to include information not just about faults that have arisen, but also better

42 Danzon, above n $1,36$.

43 Duffy, Barrett and Duggan, above n 34, 5.68 and 6.74.

44 Bottrill v A [2001] 3 NZLR 622 (CA).

45 It is noted that Dr Bottrill voluntarily retired from practice in 1996.

Re Parry (8 September 2000) Medical Practitioners Disciplinary Tribunal 129/00/62 D.

47 Director of Proceedings $v$ Harrild (20 June 2001) Medical Practitioners Disciplinary Tribunal 163/01/70D

48 Helen Cull Review of Processes Concerning Adverse Medical Events (Ministry of Health, Wellington, 2001). See also Howell, above n 3 .

49 Danzon, above n 1. 
information about systems and actions that deliver acceptable outcomes. However, these unique incentives are effective only when all agents who can potentially contribute to the incidence of costs are included in the scope for attributing fault.

The limited rights to take action against medical practitioners in cases of medical misadventure in New Zealand exist primarily through the Medical Practitioners Disciplinary Tribunal and other professional disciplinary associations, and through civil action in the case of deliberate harm or gross negligence. Administrative agents who contribute to the costs of medical misadventure as a result of their actions, incentivised by the system under which they operate and which they may have designed themselves, face no such liability. Indeed, politicians and some public service agencies are specifically shielded from liability. ${ }^{50}$ Thus, it can be argued that some muted incentives apply to medical practitioners to exert care, yet those who design and operate the organisational and institutional systems under which the medical practitioners operate are exempt. In the event of any fault-attributing action being taken, any immunity of other agents may result in the costs of poor actions and decisions of all participants in the process being borne exclusively by the medical practitioner.

Professional disciplinary tribunals have no power or authority to make any findings beyond the practitioner's professional competence. The only person the tribunal can discipline is the practitioner, so the incentive effects of tribunal decisions pertain only to medical practice. Even if the tribunal process reveals contributory fault in other parties, there is no chain of accountability requiring others to act on the basis of these findings. Unless contributory fault can mitigate the costs borne by the practitioner, the medical practitioner risks bearing the costs of the actions of others over which they have no control and which they are powerless to share with the responsible parties. The practitioner can become a scapegoat for all of the costs that arise out of the incentiveless system. These costs can have extremely significant impacts given the role that personal reputation plays in the ability of medical practitioners to derive an income in the future. ${ }^{51}$

Again, the Bottrill case provides an example in the New Zealand context. The costs of Dr Bottrill's negligence were higher as a consequence of administrative failings, yet it is difficult to see where those responsible for administrative failings could have been individually held to account to an extent that would have resulted in higher incentives for future agents to increase levels of ex ante precaution or increase flows of relevant information in the future provision of services in relation to other system designs or service delivery. The scope of the Ministerial Inquiry was constrained by its terms of reference to facts relating specifically to the National Cervical Screening Programme,

50 The Crown Proceedings Act 1950 insulates politicians (including Ministers of the Crown), as agents of the Crown, from personally bearing the costs of their deliberately opportunistic actions. Any liability of individual Ministers is underwritten by the Crown. Members of Parliament acting in the House are immune from criminal or civil proceedings.

51 Danzon, above $\mathrm{n} 1$. 
and to establishing facts and providing recommendations only as far as they related to those facts. Consequently, it had no powers of individual sanction and was limited in its ability to address wider issues of health and judicial system design and financing. The only possibility of imposing costs on administrative agents lay in the reputation effects upon individuals called upon to give evidence. Further, even in relation to identified faults within its terms of reference, accountability for the Inquiry's findings have proved difficult to enforce. It is significant that, nearly three years after the Inquiry made its recommendations, the audit of the Cancer and Cervical Screening registers has not yet been completed.

Even though problems in relation to the National Cervical Screening Programme may have been deemed to be addressed by the Inquiry, the transferability of the findings to other potential medical misadventure circumstances appears to be negligible. This stands in contrast to a judicial process, where the accused practitioner has both an incentive and the ability to implicate those who have contributed to the extent of the loss, and where the establishment of precedent in relation to both primary and contributory negligence sets clear standards of care for all parties in the future. The very process of a Ministerial Inquiry reinforces a backward-looking approach to addressing faults only once the act has occurred and harm has been caused. This is not conducive to improved information flows or the design of other processes to reduce misadventure, and is itself affected by the same problems of lack of incentives that attend all government-provided services. ${ }^{52}$

\section{INCENTIVES FOR INFORMATION DISSEMINATION}

The nature of the New Zealand medical misadventure process appears skewed towards action occurring only once significant harm has already eventuated. It does not encourage early dissemination of information to those who, if they were in possession of the information, would alter their perceptions of the risks of receiving treatment. In a system with weak internal administrative monitoring and information processes due to severely reduced incentives inherent in system design and operation, even greater reliance is placed in practice upon the actions of "whistleblowers" to make the necessary information available to those who can act upon it early enough to reduce further rises in the already high costs of negligence and malpractice. Such reliance reduces the integrity of the system to little more than the results of a lottery. Current and future patients of negligent practitioners will receive information that prevents them from incurring higher losses only if they are lucky enough to share the practitioner with a highly-motivated patient or other agent who, with no guarantee of being able to recoup the costs of the action of sharing information, is prepared to incur the personal costs of sharing information.

It is again significant that most recent high-profile medical misadventure cases in New Zealand have emerged as a consequence of the actions of a highly-motivated victim. Witness $\mathrm{A}$ in the Bottrill case, Colleen Poutsma and Mrs A McLeod have all been quoted as saying they commenced

52 Horn, above n 16. 
their actions against practitioners after being frustrated by delays in administrative processes. Realising that other patients were continuing to be treated by the same practitioner, and having endured significant suffering themselves, all wanted to disseminate information that would inform patients of possible negligence, deter them from consulting the relevant practitioners and thereby reduce the number of other patients suffering similar (and not financially compensable) costs of misadventure. Each was sufficiently motivated to act because each was faced with premature loss of life. ${ }^{53}$ In each case, it could be asserted that the marginal cost of action was low as they had nothing of value left to lose. They could afford to be altruistic.

\section{HIGH COST CONSEQUENCES IN NEW ZEALAND}

Reliance on "whistleblowers" for the integrity of a system means that only the most serious cases of negligence and medical misadventure will receive the retrospective analysis and information revelation afforded by ex post disciplinary action. Meanwhile, less serious (in terms of loss of life) but nonetheless costly adverse events occur at rates much higher than optimal. That we do not see more high-profile cases such as the Bottrill case cannot be taken as a signal that the New Zealand system is working. Rather, the small number of cases is probably symptomatic of a systemic failure. The evidence of this is visible in the rapidly increasing costs of medical misadventure accruing to the Accident Compensation Corporation, and in studies such as those of Davis and others ${ }^{54}$ showing the extremely high incidence of hospital patients who suffer an adverse effect from a preventable action.

\section{CONCLUSION}

The New Zealand accident compensation system, in combination with the predominance of public health sector funding in New Zealand, is - from an analysis of theory and available evidence - almost totally reliant upon "whistleblowers" due to inefficiently low levels of monitoring and enforcement for detection of error. It provides minimal incentives to practitioners to take care, is likely to be prone to lengthy delays in action against malfeasant practitioners when poor standards are detected, and disincentivises the collection of information that may assist in both identifying instances of malpractice and designing better detection and prevention systems. While financial compensation and access to rehabilitation programmes are easy to obtain, this is of little comfort to patients and their families who endure the irreversible consequences of medical misadventure, many of which can never be completely compensated financially. The overall effect has been to shift risks

53 In the case of Mrs A McLeod, the life lost was that of her unborn child.

54 Adverse Events in New Zealand Public Hospitals: Principal Findings from a National Survey, above n 31; P Davis and Others "Adverse Events in New Zealand Public Hospitals I: Occurrence and Impact" (2002) 115 NZ Med J U 271; P Davis and Others "Adverse Events in New Zealand Public Hospitals II: Preventability and Clinical Contact" (2003) 116 NZ Med J U 624 
that would otherwise be borne by practitioners and administrators onto the very people whom the ACC system was designed to protect - individual patients.

The design of the ACC system in relation to medical misadventure cannot be considered in isolation from the role of incentives in inducing the optimal level of medical misadventure. Although certainty of compensation is a valid objective, it should not be pursued at the cost of lower standards of care and consequently higher levels of misadventure. Indeed, if more instances of misadventure occur, the objective of a no-fault ACC system as a deliverer of fair outcomes to disadvantaged individuals may well be thwarted by an unequal distribution of the costs of reduced levels of precaution.

In liability-based insurance and tort systems, the costs of precaution are priced into insurance premiums for medical practitioners and passed on to all patients in the form of service prices. All patients thus bear the costs of all services provided by all practitioners. In no-fault systems, there are no individual insurance requirements for practitioners. All patients enjoy lower direct treatment costs, but the additional costs of higher instances of medical misadventure are disproportionately borne by the smaller subset of patients who become victims of these adverse events. ${ }^{55}$ While higher compensation costs can be extracted via levies and taxation, personal costs that are uncompensatable cannot be shifted from the victims, who represent a larger group than if an incentive-based scheme was in place.

The ability to pursue a civil action is a powerful tool in inducing individuals to exert higher levels of precaution. Where the costs of loss are difficult to compensate, as in the case of medical misadventure (and, indeed, any of the injuries covered by ACC) the removal of incentives that reduce the level of care taken must be done with a large degree of caution. No-fault systems may be effective in delivering compensation to victims but are efficient only if the effects of reduced incentives to exercise care can be adequately offset by effective monitoring, enforcement and education mechanisms. This is a difficult challenge for any system, and may not be feasible because in most instances it is impossible to reconstruct the effects of incentives using other tools. For medical misadventure in particular, in the New Zealand context, the combination of no-fault insurance and the extremely high proportion of public funding for medical treatments may reduce the available incentives by so great an extent that an efficient level of adverse events is simply not achievable, no matter how high the level of funding dedicated to monitoring, enforcement and education. The information that would make this equilibrium possible is either simply not available or is prohibitively expensive to collect.

The preceding analysis shows that it is far from clear that the no-fault New Zealand accident compensation system provides a superior outcome in relation to medical misadventure than the

55 It is significant to note that in the New Zealand context, where nearly 80 per cent of medical costs are met from public funds, the principal beneficiary of lower prices is the government purchaser. 
schemes of any comparable country. Removing incentives is far from costless and most likely results in outcomes that are substantially less equitable. It is reasons such as these that may underpin the reluctance of other jurisdictions, especially those with substantial proportions of State spending on medical services, to emulate the New Zealand ACC "experiment". 
